Albert Anker (1831-1910)

\title{
Porträtist der Kinder
}

In der Wiedergabe von spielenden und lernenden Kindern war der schweizer Maler Albert Anker meisterhaft. In genau durchdachten Bildkompositionen wird jedes der Kinder individuell dargestellt.

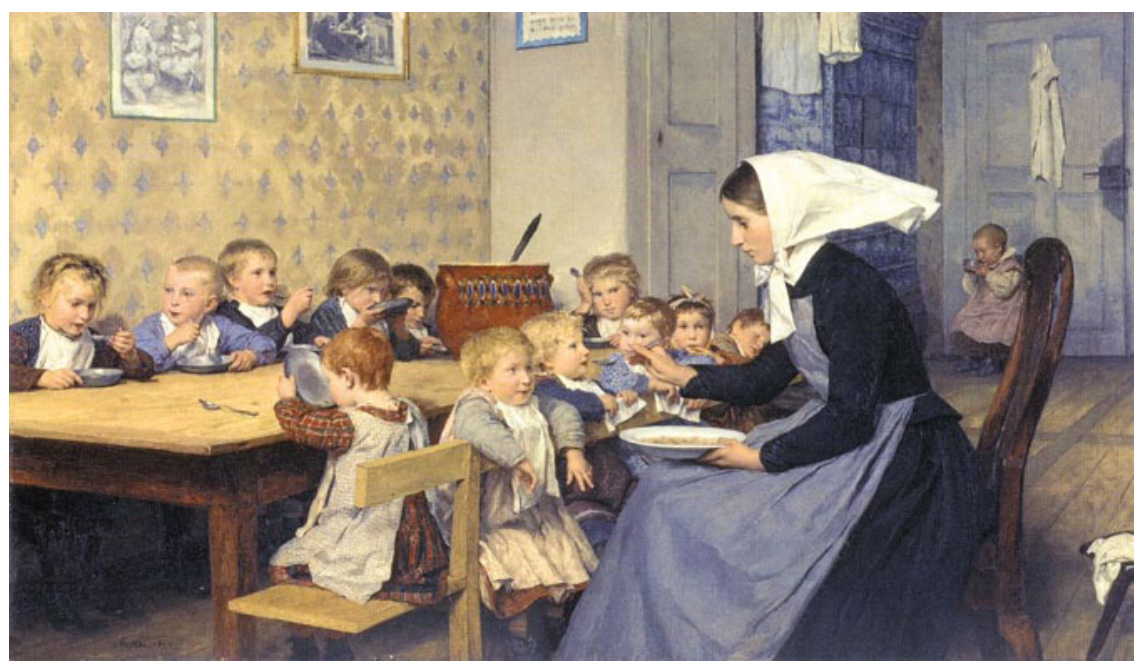

Albert Anker "Kinderkrippe“ (1890)

$\mathrm{K}$ inder und die meisten Erwachsen sind vom Schnee fasziniert und fangen spontan damit an, ähnlich wie mit Sand, Figuren zu formen. Und stolz zeigen sie ihre Kunstwerke. Dass der Schweizer Kindermaler Albert Anker 1873 in seinem Wintergemälde auf unserem Titel einen Schneebären statt einen sonst üblichen Schneemann malte und in den Mittelpunkt stellte, liegt daran, dass er seine meiste Zeit in Bern verbrachte und der Bär ähnlich wie für Berlin auch für Bern das Wahrzeichen darstellt.

Die Dorfszene im winterlichen Ins zeigt einen riesigen, fast vollendeten „Schneemutz", der sicher ursprünglich als Schneemann gedacht war und dann zum Wappentier umgewandelt wurde. Er wird hier nur von einem auf dem Stuhl stehenden Jungen bearbeitet. Alle anderen Kinder, offensichtlich aus der Schule kommend, stehen überwiegend staunend um das Kunstwerk herum. Es lohnt sich, die einzelnen Gesichter und die Details des 90 x
$150 \mathrm{~cm}$ großen Bildes zu betrachten und sich auch Gedanken über den aus dem rechten Bildrand hinausgehenden alten Mann zu machen. Das etwas gestellt wirkende Gemälde hatte Anker mit bereits im Januar 1871 beginnenden Vorstudien detailliert geplant.

\section{Kinderspiel neu entdeckt}

Kein anderer Maler hat sich im 19. Jahrhundert so intensiv mit dem Motiv des spielenden und lernenden Kindes befasst wie Albert Anker, der 1831 als Sohn eines Tierarztes in Ins auf die Welt kam. In Ins verbrachte er auch seine Kindheit und Jugend bis er vorübergehend Theologie studierte und dann ab 1854 endlich Maler werden durfte. Das Thema Schülerdasein als Lebensform hatte sich in der zweiten Hälfte des 19. Jahrhunderts zu einem eigenen Genre entwickelt, das in einem großen Kundenkreis im In- und Ausland lange Zeit viele Freunde und damit Käufer fand. Die Schweizer Sozialreformer
Johann Heinrich Pestalozzi (1746-1827) und Jacques Rousseau (1712-1778) sowie der deutsche Reformpädagoge Friedrich Fröbel (1782-1852) hatten die Kindheit, deren Entwicklung und die Erziehung mit der Bedeutung des Kinderspiels neu entdeckt. Anker war davon tief beeindruckt und hatte als Theologiestudent sogar einen Vortrag darüber gehalten.

Von Anker gibt es nicht nur unzählige Porträts von Kindern in verschiedenen Lebenssituationen vor allem auf dem Lande und in Verbindung mit Lernen und Schule, sondern er malte immer wieder Gruppenbilder in Kinderkrippe (Abb.), Vorschule und Schule. Dabei zeigt er jedes Kind in seiner Eigenart, ob freudig interessiert, verspielt oder verträumt; kein Kind steht abseits oder wird ausgeschlossen. Meist sind seine Bildkompositionen genau durchdacht, jedes Kind in seiner Individualität charakterisiert. Erst die beginnende Fotografie verdrängte diese Bildgattung. In Ankers Schulgemälden scheinen die Schülerinnen und Schüler durch ihre Haltungen und Blicke zu sprechen. 1858 malte er die „Dorfschule im Schwarzwald“, mit der er erstmals im Pariser Salon auftrat, in der noch der strenge Dorfschullehrer mit Rohrstock zu sehen ist. Dagegen zeigte er vier Jahre später die neuen Veränderungen in seinem Schulgemälde „Das Schulexamen“.

Anker übernahm 1860 das elterliche Inser Wohnhaus und heiratete vier Jahre später Anna Ruefli aus Biel, die beste Freundin seiner jüngsten, viel zu früh verstorbenen Schwester Luise. Im Dachstuhl des Hauses, das inzwischen als $\mathrm{Mu}$ seum eingerichtet ist, kann man in seinem ehemaligen Atelier noch viele seiner Requisiten wie Spielzeug, Puppen, Tassen, Kaffeekannen und Geschirr sehen, die er für seine Gemälde benötigte. Im Sommer entstanden hier meist die Entwürfe für seine Bilder, die er dann in den Wintern in seinem Pariser Atelier fertigstellte. Die Familie begleitete ihn bis zum Jahre 1899, die Kinder gingen dann dort zur Schule. 1900 bekam Anker von der Universität den Ehrendoktor verliehen, 1901 erlitt er einen Schlaganfall, der eine Lähmung der rechten Hand zur Folge hatte. So konnte er in den letzten zehn Jahren nur noch kleinformatige Bilder mit seiner linken Hand malen, bevor er am 16. Juli 1910 in Ins verstarb. 